\title{
Automated enzymatic fluorometric method for the determination of pyruvic and lactic acids in blood
}

\author{
D. G. CRAMP \\ From the Alexander Simpson Laboratory for Metabolic Research, St. Mary's Hospital Medical School, \\ London
}

SYNOPSIS A simple automated fluorometric method for the estimation of lactate and pyruvate is described. Analyses can be performed at 60/hour and can conveniently determine pyruvate and lactate in the ranges $0-5 \mathrm{mg}$. and $0-30 \mathrm{mg} / 100 \mathrm{ml}$. The methods give a high degree of analytical precision and good yields from recovery experiments.

In studies in intermediary carbohydrate metabolism in this laboratory (Wynn and Doar, 1966) the need has arisen for the accurate and rapid determination of blood pyruvic and lactic acids. Enzymatic methods for estimating these intermediaries are well established (Bergmeyer, 1963) and commonly utilize a nicotinamide-adenine dinucleotide (N.A.D.) lactate dehydrogenase (L.D.H.; EC 1. 1. 1. 27, L-lactate; N.A.D. oxidoreductase) coupled system with measurement spectrophotometrically of the increase or decrease of reduced N.A.D. in the reaction. Reduced N.A.D. has a characteristic native fluorescence, whereas the corresponding oxidized form has not (Lowry, Roberts, and Kapphahn, 1957; Greengard, 1956): this distinction between the reduced and oxidized N.A.D. forms the basis of a simple procedure for estimation of pyruvic and lactic acids by measuring change in fluorescence of N.A.D. $\mathrm{H}_{2}$ involved in the reversible lactate dehydrogenase catalysed reaction:

pyruvate + N.A.D. $\mathrm{H}_{2}+\mathrm{H}^{+} \rightleftharpoons$ lactate + N.A.D. (Neilands, 1955).

At $p \mathrm{H} 7 \cdot 4$ in the presence of excess N.A.D. $\mathrm{H}_{2}$ the equilibrium strongly favours formation of lactate, the pyruvic acid being reduced almost quantitatively. At $p \mathrm{H} 9.6$ the reverse reaction occurs, with formation of N.A.D.H , $_{2}$ and the quantitative conversion of lactate to pyruvate. The reaction goes to completion at this $p \mathrm{H}$ if a ketone trapping agent such as hydrazine or semicarbazide is used to fix the pyruvate.

This paper describes a simple, speedy automated procedure for fluorometric assay of pyruvate and

Received for publication 21 April 1967. lactate, which provides an alternative to other automated enzymatic methods, e.g. that of Antonis, Clark, and Pilkington (1966) for lactate and pyruvate, and of Hochella and Weinhouse (1965) for lactate.

\section{MATERIALS}

\section{REAGENT SOLUTIONS}

0.6 M Perchloric acid

0.4 M Triethanolamine hydrochloride buffer, pH 7.4 Triethanolamine hydrochloride, $74.4 \mathrm{~g}$., and $3.7 \mathrm{~g}$. E.D.T.A.-Na salt are dissolved in about $800 \mathrm{ml}$. distilled water. The solution is adjusted to $p \mathrm{H} 7 \cdot 4$ with saturated sodium hydroxide, and made up to 1 litre with distilled water.

$0.5 M$ Glycine buffer, containing $0.2 M$ hydrazine, pH 9.6 Glycine, 37.5 g., 20.5 g. hydrazine hydrochloride, and 2 g. E.D.T.A.-Na salt are dissolved in distilled water, the $p \mathbf{H}$ is adjusted to $\mathbf{9 . 6}$ with saturated sodium hydroxide, and the solution made up to 1 litre with distilled water.

Pyruvate standard Lithium pyruvate, $37.5 \mathrm{mg}$. ( $\equiv 100$ $\mathrm{mg} / 100 \mathrm{ml}$. pyruvic acid), is dissolved in $100 \mathrm{ml}$. distilled water. Dilutions are made to give a range of working standards $0-5 \mathrm{mg} . / 100 \mathrm{ml}$.

Lactate standard Zinc sarcolactate, $55 \mathrm{mg}$. ( $\equiv 100$ mg. $/ 100 \mathrm{ml}$. lactic acid), is dissolved in $100 \mathrm{ml}$. distilled water. Dilutions are made to give a range of working standards $0-30 \mathrm{mg} . / 100 \mathrm{ml}$.

The buffer solutions are filtered before use through fritted glass filters of fine porosity. This is important as it removes dust and other possibly fluorescent particles.

Enzyme-coenzyme reagent The enzyme and coenzymes are obtained from Boehringer Corporation (London) Ltd. The L.D.H. is a crystalline suspension of heart muscle enzyme in $2.2 \mathrm{M}$ ammonium sulphate and is used without further treatment. Its specific activity is about 360 units/milligram of protein. 
Sampler $2: 60$ per hour : cam 1:2

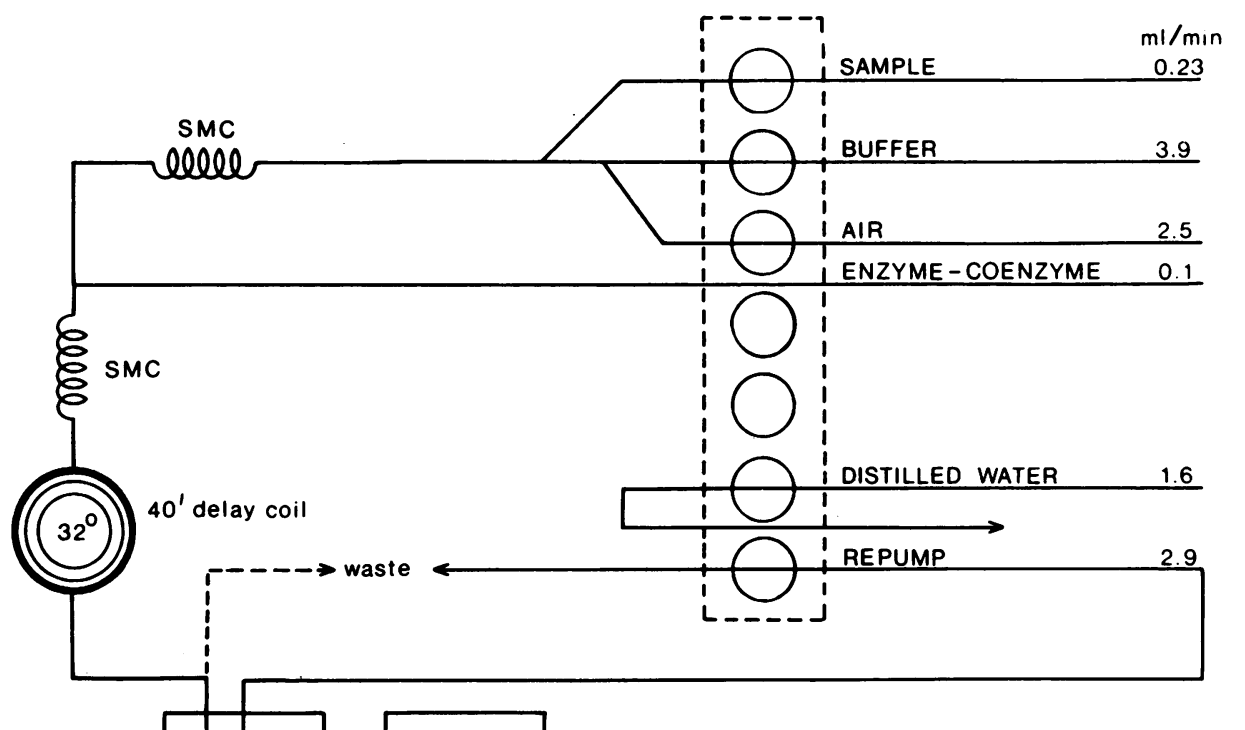

FIG. 1. Flow diagram for measurement of pyruvate and lactate by an automated fluorometric method.

FLUORIMETER

$1^{\text {ry }}$ filter 360

$2^{\text {ry }}$ filter 470

\section{METHOD}

PYRUVATE ESTIMATION For pyruvate estimation to $10 \mathrm{ml}$. of $0 \cdot 1 \mathrm{M}$ phosphate buffer, $p \mathrm{H} 7 \cdot 4$, are added $2 \cdot 5$ mg. N.A.D. $H_{2}$ together with $2.5 \mathrm{mg}$. (as protein) of lactate dehydrogenase.

LACTATE ESTIMATION For lactate estimation to $10 \mathrm{ml}$.

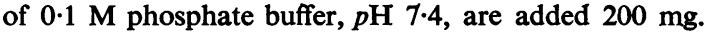
N.A.D. together with $10 \mathrm{mg}$. (as protein) lactate dehydrogenase.

The enzyme-coenzyme solutions are made up freshly in sufficient quantities for each batch of analyses, and are kept refrigerated during assay by placing in a crushed ice bath, otherwise there is loss of activity of about $2 \%$ per hour. The solutions are made up in $10 \mathrm{ml}$. or multiples thereof, each $10 \mathrm{ml}$. being sufficient for analysis of approximately 100 samples.

INSTRUMENTATION A Technicon AutoAnalyzer sampler II and proportioning pump, a $32^{\circ} \mathrm{C}$. heating bath containing a 40 foot delay coil, a Locarte single-sided fluorimeter mark $\mathrm{V}$ fitted with flow cell, and a $10 \mathrm{mV}$ potentiometric recorder comprised the instrumental system. The fluorimeter was fitted with a $360 \mathrm{~m} \mu$ primary filter and a $470 \mathrm{~m} \mu$ secondary filter. No modification of any module is required, except that a $5 \mathrm{k}$ ohm resistance is required across the fluorimeter-recorder outlet. 
60 per hour with distilled water as wash, and using a $1: 2$ sample wash ratio cam.

\section{RESULTS}

The analytical ranges of the method are $0-5 \mathrm{mg}$. and $0-30 \mathrm{mg}$. for pyruvic and lactic acids respectively, and both produce linear calibration curves.

The analytical reproducibility of the method is good, and was checked by performing duplicated analyses on 50 samples. For pyruvate the standard error of a single sample ${ }^{1}$ was \pm 0.004 , the mean difference between duplicates being 0.03 over the range $0-5 \mathrm{mg}$., and for lactate over the range 0-30 $\mathrm{mg}$. the standard error of a single sample was \pm 0.026 with a mean difference of $0 \cdot 13$.

Results obtained for pyruvate assay (100 samples) were compared with those obtained by a manual spectrophotometric enzymatic method (Landon et al., 1962). The results were indistinguishable.

Recovery of lactate in 20 experiments averaged $97 \%(96-98 \%)$ over the range $0-30 \mathrm{mg} . / 100 \mathrm{ml}$, and of pyruvate $99 \%(98-101 \%)$ over the analytical range of $0-5 \mathrm{mg} . / 100 \mathrm{ml}$.

\section{DISCUSSION}

Both methods are highly specific for their respective substrates. Only L- ${ }^{+}$) lactic acid (sarcolactic acid) reacts, D-lactate does not. In similar amounts $\alpha$-hydroxybutyrate and $\beta$-chlorolactate could enhance analytical results but these substances are rare. Meister (1950) pointed out that muscle L.D.H. is not entirely specific, in that other $\alpha$-keto and $\alpha, \gamma$-diketo acids may react at around neutral $p \mathrm{H}$; however, their reaction rates are so slow that their contribution can be regarded as insignificant.

Many workers have noted the rapid loss of pyruvate from blood samples on shedding (Huckabee, 1956; Bueding and Wortis, 1940; Gloster and Harris, 1962; Landon et al., 1962) and have endeavoured to overcome this with immediate deproteinization. It has further been noted that using perchloric acid as deproteinizing agent there is incomplete recovery of added lactate or pyruvate, and trichloroacetic acid has been substituted because of better recovery yields. The technique of Landon et al. (1962) has overcome these difficulties using perchloric acid, and there are good recoveries of both lactate and pyruvate.

${ }^{1}$ Calculated as the standard error of a single determination $\mathrm{e}=\sqrt{\frac{\Sigma \mathrm{d}^{2}}{2 \mathrm{~N}}}$, where $\mathrm{d}$ is the difference between two single tests performed on each sample, and $\mathbf{N}$ is the number of double determinations.

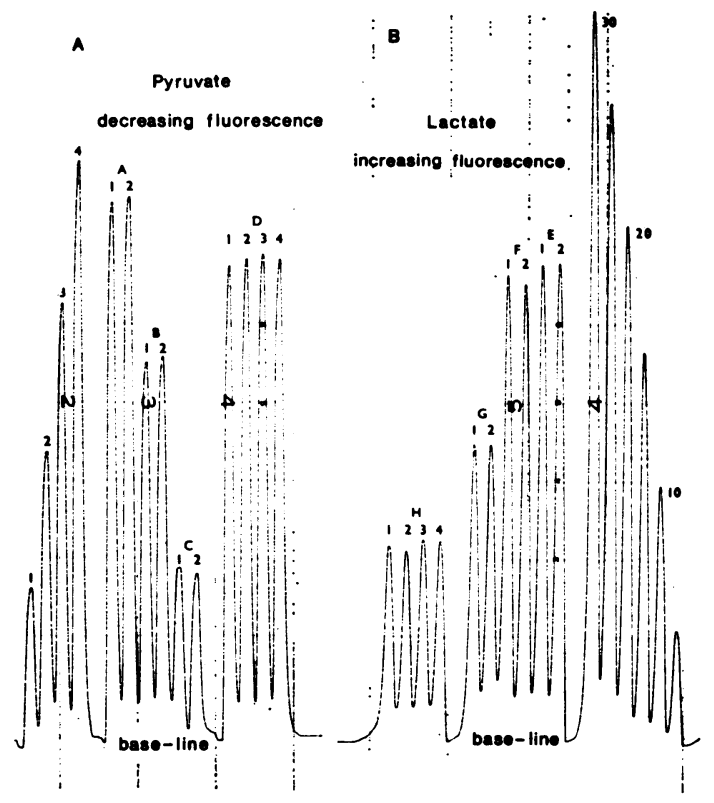

FIG. 2. Recordings showing calibration curves (mg./100 $\mathrm{ml}$.); reproducibility of paired samples of $(A)$ pyruvate, (B) lactate.

The pyruvate standard was made up from commercial lithium pyruvate. Stock solutions of several pyruvate salts were compared and all gave similar analytical results, and all were stable several months in the refrigerator. A stock solution of pyruvic acid is stable for only a few days as are also the dilute working standards. Therefore working standards must be made before each batch of analyses. L-(+) zinc sarcolactate was used for standardization of the lactate method rather than the D-L salt.

In calculating the concentration of the stock standards a factor of $\frac{9 \cdot 0}{8.54} \times \frac{1}{3}$ must be applied to allow for dilution of blood in perchloric acid and for blood water. (As $3 \mathrm{ml}$. of blood contains about $2.54 \mathrm{ml}$. of water the volume of solution after deproteinization is $8.54 \mathrm{ml}$. rather than $9 \mathrm{ml}$.) In the case of pyruvate $3 \%$ is added to correct for loss of pyruvate (Huckabee, 1956) in the oneminute interval between shedding and deproteinization.

The $p \mathbf{H}$ of buffers, incubation coil temperature, reagent concentrations, and flow rates were determined by considerable preliminary trial. Initially, enzyme, coenzyme, and buffer were mixed as a single solution, but this resulted in rapid denaturation of enzyme. This was obviated by making up small quantities of concentrated enzyme-coen- 
enzyme solutions and refrigerating in ice during analysis. The incubation coil temperature of $32^{\circ} \mathrm{C}$. was chosen as enzyme denaturation is much reduced compared with $37^{\circ} \mathrm{C}$. at which temperature blocked lines are common.

As shown by the precision of the method reproducibility is good, for there is little or no crosscontamination of samples (Fig. 2). The proposed method gave pyruvate results that were indistinguishable from those obtained by a manual spectrophotometric method previously reported from this laboratory (Landon et al., 1962).

The method has been in use in this department for over one year and has proved reliable, precise, and economical.

I wish to thank Dr. V. Wynn, Reader in Human Metabolism, for permission to carry out and publish this work, also Dr. J. W. H. Doar for advice, and Miss G. Robertson for preparing the figures and performing the manual analyses.

REFERENCES

Antonis, A., Clark, M., and Pilkington, T. R. E. (1966). J. Lab. clin. Med., 68, 340 .

Bueding, E., and Wortis, H. (1940). J. biol. Chem., 133, 585.

Bergmeyer, H. V. (Editor). (1963). Methods of Enzymatic Analysis, pp. 253 and 266. Academic Press, New York and London.

Gloster, J. A., and Harris, P. (1962). Clin. chim. Acta, 7, 206.

Greengard, P. (1956). Nature (Lond.), 178, 632.

Hochella, N. J., and Weinhouse, S. (1965). Analyt. Biochem., 10, 304. Huckabee, W. E. (1956). J. appl. Physiol., 9, 163.

Landon, J., Fawcett J. K., and Wynn, V. (1962). J. clin. Path., 15, 579.

Lowry, O. H., Roberts, N. R., and Kapphahn, J. I. (1957). J. biol. Chem., 224, 1047.

Meister, A. (1950). Ibid., 184, 117.

Neilands, J. B. (1955). In Methods in Enzymology, edited by S. P. Colowick and N. O. Kaplan, vol. 1, p. 449. Academic Press, ? New York and London.

Wynn, V., and Doar, J. W. H. (1966). Lancet, 2, 715. 